Hum. Dev. 1981;24:77

\title{
In Memoriam Jean Piaget
}

\section{August 9, 1896-September 16, 1980}

A man of singular purpose and great vision Who dared to bring down to earth what philosophers had kept in the clouds, Who humanized a barren psychology that had the illusion it could function without a philosophical framework. An innate rationalist to some psychologists, A biological experimenter to most philosophers, An idealist to dialectic thinkers, A relativist to positivists, He has single-handedly shown a way To bridge the baneful split

Between knowing and acting Between subject and object Between heredity and environment By establishing the science of genetic epistemology: He has given empirical substance to the theory of knowledge

Through observing its development in infants and children And confirmed Kant's a priori By rooting it in biology

But putting it at the end, not at the beginning of the evolutionary history. Hans Furth 